\title{
Interface Educação
}

\section{AVALIAÇÃO VERSUS PRÁTICAS EDUCATIVAS}

\author{
Mário Jorge de Araújo Gonzaga (1) \\ Mônica Maria Siqueira Damasceno (2) \\ Ana Cristina de Oliveira e Silva (3) \\ Rita Edevanira de Sá Carneiro (4)
}

\begin{abstract}
Resumo
Pensar, discutir, fundamentar, analisar, redimensionar, conceituar avaliação no processo de aprendizagem envolve primeiramente uma filosofia que embase o trabalho educacional fundado na concepção de currículo, pois uma das questões básicas para que haja superação da visão fragmentada de ensino que predomina em nossas escolas, uma vez que não se consolida uma filosofia de trabalho de formação que contemple o eixo articulador de todas as atividades didáticas da escola, para que se defina o papel de cada atividade na trajetória a ser percorrida pelo professor e alunos na sala de aula.Somente a partir de um paradigma norteador dessas atividades, partilhado entre todos que fazem o processo, a avaliação se estabelece no seu sentido próprio.
\end{abstract}

Palavras-chave: Educação, práticas educativas, Avaliação.

\section{Introdução}

O processo de avaliação é indissociável do ensino, pois este contempla a estrutura e a dinâmica das escolas, buscando a formação de pessoas, cidadãos, em que cada disciplina com seus objetivos integrados e harmonizados no conjunto (ALMEIRA, 1998). Isso, em função das metas mais abrangentes a atingir e dentro de um contexto definido para que a avaliação adquira um sentido específico, orientado para o papel da escola.

Como afirma Gatti (2003):

[...] um bom ensino só se processa em um ambiente em que a integração curricular é vivenciada coletivamente e um processo de avaliação de alunos adquire seu pleno 
sentido no âmbito desta totalidade e na especificidade do papel que cada atividade ou disciplina tem no concerto do conjunto a que pertence.

Nessa perspectiva, é de grande relevância que para o professor fiquem claros os aspectos mais importantes a avaliar, não na direção apenas do tópico específico de que trata, mas de seu significado na formação das crianças e jovens, numa perspectiva mais amplamente compreendida .

Segundo Darsie (1995), um outro aspecto a se evidenciar é a perceptível diferença entre o conceito de medir e avaliar. Quando se mede algum fenômeno por intermédio de uma escala, de provas, de testes, de instrumentos calibrados ou por uma classificação ou categorização, apenas esta se levantando dados sobre a grandeza do fenômeno, como um número e uma freqüência em uma categoria.

Na verdade só se conhece o sentido dessas grandezas se, tiver algum critério de referência, pois para termos uma avaliação é preciso que se construa o significado destas grandezas em relação ao que está sendo analisado quando se considera como um todo, observando-se suas relações com outros fenômenos, suas características historicamente consideradas, o contexto de sua manifestação, dentro dos objetivos e metas definidos para o processo em avaliação, considerando os valores sociais envolvidos. Nesse sentido, endossa Amorim e Souza (apud GATTI, 2003):

\footnotetext{
Avaliação não é algo que se dê de modo dissociado do objeto ao qual se dirige e não se concretiza independentemente dos valores dos sujeitos em interação. Assim, os princípios norteadores de uma proposta avaliativa e de seu próprio processo de construção representam uma explicitação do posicionamento de sujeitos frente a um determinado segmento da realidade, sujeitos esses que ocupam diferentes lugares sociais, o que leva ao afloramento de divergentes e conflitantes ênfases na avaliação.
}

Entendendo-se, dessa forma, uma avaliação como um julgamento de valor, a avaliação em sala de aula é um julgamento para se saber até que ponto aluno atingem objetivos valiosos em aprendizagens diversificadas em relação a um certo conteúdo considerado necessário ao seu desenvolvimento pessoal; como o fazem e quais atitudes e valores revelam que sejam pertinentes ao seu domínio pragmático.

Hoffmann (1994) nos orienta que, é necessário inferir, comparar, analisar consequências, examinar o contexto, estabelecer valores, aquilatar atitudes, formas de comunicação, fazer a autocrítica de valores pessoais, e, para isso, é necessário que se tenha algum suporte referencial em concepções educacionais, fundamentado em reflexões e consensos, trabalhado antes, durante e depois do processo avaliativo, o que consiste em um trabalho integrado de professores e alunos.

Portanto, somente com o exercício da docência com propósitos claros e consensuais alimentase um processo de avaliação mais consistente e, logicamente, mais integrado na direção de uma formação mais voltada para o desenvolvimento dos alunos. Não somente para cumprir uma formalidade burocrática ou mesmo para satisfazer o exercício de autoritarismos ou autoafirmações pessoais. 
Nesta perspectiva, a avaliação do aluno precisa ser continuada, variada e, com instrumentos e elementos diversificados. Deve ser utilizada no próprio trajeto do ensino, como parte deste, e direção voltada para aprendizagens cognitivo-sociais de valor para os participantes desse processo.

A avaliação normalmente absorve a melhor parte da energia dos sujeitos envolvidos. Não sobra muito para inovar. O sistema clássico de avaliar favorece uma relação utilitarista com o saber, uma vez que toda a tentativa de implantação de novas pedagogias deve voltar-se para romper com o sistema tradicional (LUCKESI, 1995).

O trabalho escolar tende a privilegiar atividades fechadas pela avaliação clássica, onde nesse contexto os conhecimentos isoláveis e cifráveis a competências de alto nível e que são exigidas aos professores, por isso os resultados negativos vem sempre na prova escrita.

A literatura sobre a questão nos envereda a aspectos, no mínimo, sugestivos. Estes ajudam na reflexão sobre a condução das avaliações em sala de aula. Depoimentos de alunos testemunham com freqüência que eles nem sempre percebem como o docente concebe a avaliação e, qual seria seu papel na aula, para além de "dar uma nota". A maioria dos estudos tratam também que alto percentual dos discentes não consegue explicitar os critérios das "notas" que seus professores atribuem.

Colocam, também, que questões com palavras vagas ou questões excessivamente detalhadas ou complexas levam à confusão e, como resultado, eles, alunos, não podem mostrar o que sabem sobre a matéria, mas sim, quanto eles são bons em tentar compreender que o professor quer (SAUL, 1994; VEIGA, 2005; TARDIF, 2001) . Isto vale tanto para questões abertas, quanto para itens fechados, nos quais têm que entender o que é pedido pelo professor na formulação do item e também o que cada alternativa quer dizer. É frequente, nestes estudos, a observação de que o professor sempre pode "pegar" os alunos, mesmo com testes, basta que faça questões capciosas ou ambíguas ou com alternativas confusas.

Pesquisas realizadas com professores mostram que não há uma maneira universal, única ou melhor para avaliar os alunos em classe (VASCONCELOS, 2000). As provas são vistas pelos docentes como um instrumento que mede a aprendizagem e são praticamente o único tipo de instrumento de que se valem para a avaliação. Assim, percebe-se que varia o grau em que estes usam as provas como meio de ensino e também de aprendizagem, como forma de obter informações relevantes sobre o processo de desenvolvimento escolar dos alunos e sobre seu próprio processo de ensino, mas o que se constata é que a maioria dos professores não têm essa consciência nem conceito de avaliação, ficando esta restrita apenas a um processo de verificação que se baseia em concepções nem sempre claras sobre o que julga que os alunos devam ter retido, sintetizado ou inferido dos conteúdos abordados em sala de aula.

Dessa forma, nem todos os mecanismos utilizados pelos professores são suficientes para garantir o ensino aprendizagem, a elaboração das provas e sua correção representam um fardo bem conhecido no trabalho solidário dos docentes. Uma boa parte das horas de trabalho em aula e destinada à administração de provas escritas, mas o insuficiente para elaborar atividades avaliativas. 
Conforme Perrenoud (1999,p.71-72) :

A avaliação não e, em principio, um objetivo em si, mas um meio de verificar se os alunos adquiríramos conhecimentos visados. Recomenda, todavia quando se ensina ler uma ideia bastante precisa da maneira como se procedera para avaliar os conhecimentos, o que evita introduzir uma grande ruptura entre os conteúdos e as modalidades do ensino e as exigências no momento da avaliação.

Vê-se que, geralmente, a avaliação privilegia os saberes e as competências que podem se traduzir em competências em desempenhos individuais e se manifestar por meio das questões múltiplas escolha ou exercícios aos quais se pode imparcialmente atribuir um certo numero de pontos. Desse mondo, o maior problema da escola e alterar conforme as atividades de ponderação das exigências.

As idéias de Perrenoud (1999), ainda confirmam:

A avaliação não impede as transformações de programas, mesmo que limite sua operacionalização efetiva, em particular no caso da matemática de conjuntos e das abordagens comunicativas da língua. Tampouco impede a adoção de novos meios de ensino, novos métodos de aprendizagem, novas tecnologias audiovisuais ou informáticas. Essa mudança tem um ponto em comum - modernizam as praticas pedagógicas sem questionar seus fundamentos.

De maneira possível, o processo avaliativo deve ser diagnostico e formativo, desde que seja diferenciado para atender aos desejos dos alunos e da escola. E preciso compreender o sentido do ensino para que se possa aplicar nova avaliação formativa. Cabe ao professor refletir sobre as novas teorias da aprendizagem.

Ensinar e esforçar-se para o processo de aprendizagem e assim possa ter o domínio de um currículo definido, para isso e preciso o mínimo de regulação dos processos de aprendizagem no decorrer do ano escolar. Tudo isso passa por intervenções corretas, baseadas em uma apreciação dos progressos e do trabalho dos alunos. Essa condição modifica os ritmos do ensino em função do trabalho desenvolvido com objetivos fixados e diversificado, mas realizado com intenção formativa.

Para compreender as representações que subentendem uma avaliação continua parcialmente formativa, deveria a escola repensar as práticas avaliativas em sala de aula, principalmente revendo a teoria e a pratica adotada pelo projeto pedagógico. E preciso uma avaliação formativa, essa permite a compreensão maior do processo.

Nesse sentido Perrenoud (1999,P.89):

Avaliação formativa se define claramente como fonte de regulação, surge uma questão: ela e a única ou e uma fonte de regulação dentre outras. Não se deveria reconhecer que a regulação dos processos de aprendizagem pode surgir das intenções entre os alunos, tal como permitida e delimitada pelo dispositivo e pela sequiência didática, ou então surgir da atividade meta-cognitiva do aluno. 
Nesse trajeto vê-se qual a avaliação forma pessoas por meio de inferências, comporta um avanço para o processo ensino aprendizagem e, ainda compreende uma regulação global dos processos dispostos no ambiente de aprendizagem. Tudo isso por meio de uma trajetória que persegue a objetivo do ato educativo.

E natural que os estudiosos da didática ou da avaliação, consigam chegar, o mais longe possível, na construção conceitual e no desenvolvimento de modelos de avaliação para a escola no dia a dia de sala de aula.

A avaliação formativa evoluirá, portanto, como diferenciação do ensino, com o nível de formação pedagógica e outros motivadores.

Uma avaliação somente formativa somente formativa se delineia em uma forma de regulação que precisa da disposição do professor para as atividades qualitativas sobre os processos de aprendizagem, as atitudes e aquisições dos alunos. Caso ele não possa fazer, por que gastar energia e criar frustrações inúteis (interrogar) E preciso organizar turmas, espaços e horários como também outros itens importantes na construção do conhecimento.

Assim Perrenoud (1999,P.150):

A idéia de avaliação formativa desenvolveu-se no quadro da pedagogia de domínio de outras formas de pedagogia diferenciada, relativamente pouco preocupadas com os conteúdos específicos dos ensinos específicos dos ensinos e das aprendizagens.

A ênfase era dada as adaptações, ou seja, a uma organização mais individualizada dos itinerários de aprendizagem, baseada em objetivos mais explícitos, coletas de informação mais qualitativa e regular, e intervenções mais diversificadas.

Portanto, trata-se de um trabalho com atitudes voltadas para as competências do aluno, por isso o aluno precisa aprender o uso e o funcionamento dos conhecimentos adquiridos em sala de aula. Não ser importante se o aluno só aprende e não coloca em pratica no seu cotidiano, este terá que conciliar a teoria com a pratica em seu dia a dia.

Toda a avaliação formativa baseia-se na preposição de que o aluno quer aprender e deseja ajuda, sendo que pra isso este devera esta pronta pra revelar suas duvidas, suas lacunas, suas dificuldades de compreensão da tarefa. Na sala de aula os professores precisam saber todas as atividades, dificuldades e desejos dos estudantes pra que possa aplicar uma avaliação condizente com os objetivos da escola e, principalmente alcançar os objetivos.

Se o professor que tenta fazer a avaliação formativa pode ter o poder de decidir, o destino do aluno, sujeito a um sistema muito seletivo, este terá todas as razões para conservar suas estratégias habituais, mobilizar sua energia para iludir. E o professor achar-se-á reforçado no uso da avaliação como instrumento de controle do trabalho e, das atitudes. Ir em direção a avaliação formativa seria renunciar a seleção, o mecanismo permanente da relação pedagógica, a não fazer os alunos viverem 
sob a ameaça da reprovação ou da relação para orientações mesmo exigentes. Isto significa mudanças muito importantes para o aluno e a escola de modo geral, afinal todo o processo busca resultados.

A avaliação formativa está a serviço da regulação individualizada das aprendizagens, sendo esta uma pedagogia diferenciada com ambições e planos de estudo.

Neste caso, a vocação da avaliação formativa e de contribuir para as aprendizagens. Acha-se, portanto, em uma lógica de ação: não e um momento de resignar com as desigualdades e dificuldades. Nada impede que a realidade resista, que o tempo passe, que o milagre não aconteça. Vale salientar que acontecem fracassos que obrigam a fazer o balanço das aquisições, então não e mais possível remediarem, deve-se realizar ações decisivas de orientação.

Não existe, a prazo, incompatibilidade de principio entre avaliação formativa e seleção. Sua articulação pratica permanece delicada. A avaliação formativa prioriza o domínio dos conhecimentos e das competências, considerando que a que a seleção e, na melhor das hipóteses, um mal necessário, jamais um fim em si ou uma vantagem. Em um sistema que se orgulha de delimitar o acesso aos saberes, de preparar inicialmente uma elite, avaliação formativa não possui lugar, pois se insere em uma vontade de democratização do ensino, vontade não apenas afirmada, mas concretizada pela adoção de uma estrutura escolar favorecendo uma relação mais clemente, tardia e possível.

Ainda que nos sistemas escolares haja menos processos seletivos, a articulação formativa e da seleção não e evidente: em um ano determinado momento, apenas no final de um ano escolar ou de um ciclo de estudos plurianual, a avaliação muda de lógica. Quando se quer ajudar o aluno a aprender, estabelece bruscamente um balanço que, sem ser definitivo, comanda decisões em curto prazo, por vezes dificilmente reversíveis. Os professores em sala de aula podem desempenhar esse duplo papel, selecioná-los sob uma avaliação formativa.

\section{Os Procedimentos Didáticos na Avaliação}

Numa perspectiva sincrônica da didática, esta se apresenta ou como uma disciplina de ações proposital para auxiliar a pedagogia do professor, baseada nas ciências de referencia e nas ciências da educação, ciência dos fatos didáticos, da formalização, da transposição, da negociação, da apropriação, ou da avaliação dos saberes no próprio sistema didático.

Essa perspectiva inovadora mostra uma ruptura com as abordagens tradicionais 'e de forma total, pois valoriza amplos conhecimentos, a transposição didática e sua apropriação pelos alunos se fundem em conhecimentos, métodos e procedimentos racionais.

Em meio a tantas mudanças, a demonstração do ensino será uma pratica de acesso a educação escolar, mas para isso "e preciso ruptura com o tradicional (as praticas pedagógicas), onde essas que formam os cidadãos passivos:

Segundo Luckesi (2000,P.60-61): 
A sociedade moderna, com a civilização urbana construída ao longo de séculos de sua formação, passou a exigir a escolarização de todos os cidadãos. Mas para isso, todo cidadão, para usufruir medianamente dos bens construídos por esta sociedade, necessita da escolarização. Usufruir dos benefícios construídos pela sociedade recente pressupõe determinação de algum tipo de entendimento elaborado.

Na exigência dessa escolarização, a teoria da avaliação deve atingir os cidadãos da forma mais simples possível por meio de atos elementares. Para todas as atitudes, necessita-se do domínio da leitura, como se deslocar nas grandes cidades e necessário que você saiba ler, realizar um procedimento de deposito em um banco ou transferência de uma contra pra outra no mesmo banco ou em diferentes bancos, como também informações no seu dia a dia, sendo que muitas vezes a pessoa e bem qualificada, porem não consegue resolver simples problemas do cotidiano.

Ainda há atos complexos que o cidadão precisa, tais como participar dos bens culturais, vivenciar os prazeres decorrentes da cultura, entre outros, tudo isso circunstância o envolvimento com as informações no nível abstrato e concreto, portanto, o cidadão tem que ter alem do domínio da leitura, e preciso conhecimento de mundo.

Não será certamente, a aprendizagem da leitura sozinha que possibilitara aos cidadãos esses níveis de clareza e entendimento. Ela representa a porta de entrada para se chegar a esse patamar de compreensão e ação.

Nesse sentido a idéia de Luckesi (2000,p.62) esta em contribuir com uma sociedade emancipada, por que:

Acesso universal ao ensino e, pois, um elemento essencial da democratização e a porta de entrada para a realização desse desejo de todos nos, que chamamos por uma sociedade emancipada dos mecanismos de opressão (...) o segundo elemento que define a democratização do ensino e a permanência do educando na escola e a conseqüente terminalidade escolar.

Vê-se que a partir do conhecimento e da permanência do aluno da escola por meio de uma pratica didática reflexiva, composta de caminhos democráticos levando em conta as condições geográficas e sociais do educando.

Sabe-se que a sociedade burguesa (capitalista), estabelece estratégias para a democratização do ensino, por exemplo, o acesso a educação escolarizada para todos os cidadãos, mas essa educação tem sido falha porque se preocupa mais em ensinar conteúdos enquanto eles precisam de conhecimentos essenciais para a vida, as habilidades de compreender o mundo plural e complexo em que vivemos.

No tocante a vida econômica e profissional, dentro da sociedade em que estamos inserida, e preciso conhecer nossos deveres e direitos. Dessa forma, passaremos a viver bem melhor. 
Não será exatamente a escolarização sozinha que possibilitara aos cidadãos esses níveis de clareza e entendimento. No entanto, ela e uma ponte necessária para se chegar a um patamar de compreensão e ação.

Nesse sentido, o mínimo que se poderia pensar da democratização do ensino seria garantir a todos a possibilidade de ingressar na escola, tendo direito ao ensino, e assim as pessoas possam garantir os bens que esta na sociedade, úteis ao bom-viver:

Segundo Luckesi(2000,P.62):

\begin{abstract}
A Revolução Francesa, enquanto revolucionaria, propôs e apregoou o acesso universal ao ensino, porem a sociedade burguesa, sedimentada com a revolução, não so não sumpriu esse ditame revolucionário, como criou subterfúgios que impediram aos cidadãos o acesso a esse beneficio. Foram muitos os mecanismos pelos quais os poderes constituídos, representando os interesses da sociedade burguesa, subtraíram as camadas populares do acesso a educação escolarizada.
\end{abstract}

Com essa mudança, pensa-se numa escola para todos, porem limitada, porque para se colocar em pratica os atos concretos de uma escola democrática, muitos recursos técnicos e humanos são falhos, dessa maneira, o primeiro elemento da democratização, e a educação escolar.

O segundo elemento centralizou-se na permanência do aluno na escola e a conseqüente terminalidade escolar. Neste caso, o educando deve ter condições facilitadoras para permanecer na escola ate o nível superior, de forma significativa, tanto do ponto de vista individual quanto social.

Essa realidade e valorativa para a vida escolar, embora as leis educacionais brasileiras não tenha sido aprovadas garantindo essa permanência, apenas deixando brechas na lei que permite o ensino com o mínimo necessário, provocando assim a evasão e a repetência escolar, principalmente mostrando dados educacionais tristes, por exemplo, de 1000 crianças que ingressam na escola apenas 7 delas chegam ate uma Universidade.

No terceiro item da democratização do ensino esta afeto a questão da qualidade e da apropriação ativa dos conteúdos escolares.

Conforme Luckesi (2000,P.65):

Será democrática a escola que possibilitar a todos os educandos que nela tiverem acesso uma apropriação ativa dos conteúdos escolares. Ou seja, se uma criança se matricula na escola, ela tem o objetivo de conseguir aprender conteúdos que desconhece, ela pretende elevar o seu patamar de compreensão da realidade.

Em meio a esse contexto, fica claro que a pratica escolar no professor precisa se pautar em meios efetivos em que os educandos possam ser protagonistas de seu processo de ensino aprendizagem.

A avaliação é formativa se na concepção do professor, pode contribuir para uma regulação das aprendizagens em curso no sentido dos domínios almejados.A relevância desse processo se estabelece quando se tenta descrever a parcela de avaliação formativa em qualquer prática pedagógica, 
independentemente de qualquer outra referência aos vocabulários especializados e aos modelos prescritivos, porém não se pode descartar desse valioso processo os protagonistas, que são o aprendiz para aprender, um professor para organizar e gerir as situações didáticas.Nessa abordagem, considerase, pois como formativa toda prática de avaliação contínua que pretenda contribuir para melhorar as aprendizagens em curso, qualquer que seja o quadro e qualquer que seja a extensão concreta da diferenciação do ensino. Essa ampliação corre o risco, de um ponto de vista prescritivo, de fazer com que a idéia de avaliação formativa perca seu rigor. Numa perspectiva descritiva essa ampliação abrange correntes de avaliação contínuas, sob o ângulo de sua contribuição, almejada ou efetiva, para que ocorra a regulação das aprendizagens durante o período escolar.

Ensinar é um esforço de busca para orientação, no processo de aprendizagem, para que haja o domínio de um currículo definido, com a regulação dos processos de aprendizagens no decorrer do ano escolar. Esse trajeto passa por intervenções corretoras, que são baseadas em uma apreciação dos progressos e do trabalho dos alunos. Dessa forma, conceber uma avaliação formativa é, antes que qualquer coisa, sistematizar o funcionamento do processo, para uma postura mais metódica do professor em relação ao aluno. A ideia é observar, e ajustar de maneira mais sistemática e individualizada, suas intervenções pedagógicas e as situações didáticas que propõe. Tudo isso numa expectativa de otimização as aprendizagens. Essa forma de avaliação formativa centra-se essencialmente, sobre a gestão das aprendizagens dos alunos pelo professor.

De acordo com Perrenoud, as avaliações formativas ajudam o aluno a aprender e a se desenvolver, por conta da sua participação nas regulações das aprendizagens e do desenvolvimento, no sentido de um projeto educativo. Dentro dessa perspectiva pragmática, a avaliação formativa, seria uma forma de ajudar o aluno a aprender por mediações, que retroagem sobre os processos de aprendizagem. Segundo o autor, inicialmente seria uma concepção ampla de observação, que se intitula de. observação formativa, ao invés de avaliação. Pois avaliação está tão associada à medida, à classificação, a notas nos boletins escolares, que atrapalha a contabilização do conhecimento. Para Perrenoud, observar é construir uma representação realista das aprendizagens, de suas condições, modalidades, mecanismos, e resultados. Nessas condições, a observação formativa permite orientar e otimizar as aprendizagens em curso, sem preocupação de certificar ou classificar e selecionar, uma vez que pode ser instrumentalizada ou puramente intuitiva, aprofundada ou superficial, deliberada ou acidental, quantitativa ou qualitativa, longa ou curta, original ou banal, rigorosa ou por aproximação, pontual ou sistemática. Nesse caso, não se descarta o processo de avaliar conhecimentos, fazendo balanços que possam direcionar a ação pedagógica, mensurando-se sempre o domínio alcançado.

Essa concepção de observação formativa não se associa a um tipo particular de intervenção, pois o desenvolvimento e a aprendizagem dependem de múltiplos fatores que se interceptam; não só a definição da tarefa, as instruções, o procedimento didático, mas também as condições do trabalho, o sentido da atividade ou a autoimagem, que associados aos aspectos materiais e cognitivos dão suporte ao processo. 
Há diversas estratégias que podem ser utilizadas para fazer o aluno progredir, como engajá-lo em uma nova tarefa, mais mobilizadora, por exemplo, ou mais proporcional a seus recursos. Essa estratégia tende a aliviar sua angústia, devolvendo-lhe a confiança, e proporcionando-lhes outras razões para aprender.

Astolfi, 1997 (apud GATTI, 2003) ressalta que, com ampliação da intervenção são tomadas direções complementares com os seguintes objetivos: desvincular-se dos "sintomas", para ater-se às causas profundas das dificuldades; desvincular do programa em curso, para reconstruir estruturas fundamentais ou pré-requisitos essenciais; desvincular da correção dos erros, para se interessar pelo que eles dizem das representações dos alunos, para servir-se deles como pontos de entrada em seu sistema de pensamento ; desvincular das aquisições cognitivas, para levar em conta as dinâmicas afetivas e relacionais subjacentes; desvincular do indivíduo, para considerar um contexto e condições de vida e de trabalho na escola e fora dela.

Um agravante dessa ampliação da intervenção, baseada em teoria, que responde à complexidade do real e adota uma abordagem sistêmica, encontra na prática inúmeros obstáculos: identidade e competência dos professores, falta de disponibilidade, divisão do trabalho entre professores.

De acordo com Allal 1998(apud GATTI, 2003), no âmbito da avaliação formativa e de pedagogia de domínio, há três tipos de regulação, a saber: 1) as regulações retroativas, que sobrevêm ao termo de uma sequiência de aprendizagem, mais ou menos longa, à partir de uma avaliação pontual; 2) as regulações interativas, que sobrevêm ao longo de todo o processo de aprendizagem; 3) as regulações "proativas", que sobrevêm no momento de engajar o aluno em uma atividade ou situação didática novas.

Essas três modalidades combinam-se entre si, para atingir os objetivos. No que tange à regulação interativa, é preciso associá-la a uma modalidade de direção de classe e de diferenciação do ensino. Definindo-se microssequências de trabalho, ou mesmo de ensino, pode-se levar toda regulação interativa a uma regulação proativa ou retroativa e reencontrar-se em uma lógica da antecipação ou da remediação.

Nessa forma de conceber a didática, como um dispositivo de regulação, rompe-se com uma distinção clássica entre um tempo do ensino, no sentido amplo, e um tempo da regulação. Esse esquema parece supor que se possa, com razão, dissociar dois momentos sucessivos na ação pedagógica, quando em um primeiro momento, o professor ajudaria os alunos a trabalharem melhor, na base de uma hipótese didática otimista; e, em um segundo momento, ele se dedicaria a corrigir e, ao mesmo tempo, a diferenciar essa primeira ação global, intervindo junto a alguns alunos ou subgrupos em dificuldade.

Infelizmente, as didáticas melhor concebidas parecem não assegurar as aprendizagens de grande parte dos alunos, os melhores, dos quais se diz habitualmente que aprendem, a despeito da escola e, se conformam com qualquer método pedagógico. 
$\mathrm{Na}$ diversidade dos destinos escolares, percebe-se um frustrante fenômeno que é a impotência das pedagogias para gerar na maioria dos alunos, pelo menos nos momentos compartilhados, aprendizagens à altura das ambições declaradas da escola. Essa impotência é detectada em diversas atitudes, como insistir sobre o currículo, os meios de ensino, o método, os suportes audiovisuais, a relação pedagógica, pois esses fatores não passam de tangenciais, já que o sucesso das aprendizagens se passa na regulação contínua e na correção dos erros, muito mais do que no gênio do método.

Nessa perspectiva é que se concebe a didática como um dispositivo que favorece uma regulação continua das aprendizagem, pois ela deve concernir ao seguinte registro: antecipar, prever tudo o que fosse possível, mas saber que o erro e a aproximação são a regra, que será preciso retificar o alvo constantemente, por isso que a regulação não é um momento específico da ação pedagógica, é um componente permanente dela.

E dentro desse contexto, a avaliação formativa se estabelece como uma forma de regulação, que pode ocorrer pela ação e pela interação, que segundo Weiss(apud GATTI, 2003) não se restringe às interações didáticas clássicas, mas em todas as situações de comunicação nas quais a estimulação ou a resistência da realidade não são assumidas somente pelo professor, mas por outros parceiros. Dessa forma, a aprendizagem se nutre das regulações inseridas na própria situação, que obriga o aluno, conforme as interações, a ajustar sua ação ou suas representações, a identificar seus erros ou suas dúvidas, a levar em conta o ponto de vista de seus parceiros, ou seja, a aprender por ensaio e erro, conflitos cognitivos, cooperação intelectual ou qualquer outro mecanismo.

A ação é fator de regulação do desenvolvimento e das aprendizagens porque obriga o indivíduo a acomodar, diferenciar, reorganizar ou enriquecer seus esquemas de representação, de percepção e de ação. A interação social o leva a decidir, a agir, a se posicionar, a participar de um movimento que o ultrapassa, a antecipar, a conduzir estratégias, a preservar seus interesses.

Outra alternativa é o que se chama de autorregulação de ordem metacognitiva que consiste em formar o aluno para a regulação de seus próprios processos de pensamento e aprendizagem, partindo do princípio de que todo ser humano é, desde a primeira infância, capaz de representar, pelo menos parcialmente, seus próprios mecanismos mentais; o que não exclui a avaliação explícita feita pelo professor, como um modelo de objetivação dos processos e dos conhecimentos, de explicação dos objetivos e das expectativas, embora se distancie dos critérios seguidos por remediações.

Face ás discussões aventadas, pode-se afirmar que a avaliação formadora apresenta e a avaliação formativa privilegia a autorregulação e a aquisição das competências correspondentes, pois uma avaliação só é realmente formativa quando incide numa forma ou outra de regulação da ação pedagógica ou das aprendizagens; ela não funciona sem regulação individualizada das aprendizagens, colocando à disposição do professor informações mais precisas, mais qualitativas, sobre os processos de aprendizagem, as atitudes e as aquisições dos alunos.

Nesse sentido, argumenta Gatti (2003, p.21): 
A ênfase da avaliação formativa é dada às adaptações, ou seja , a uma organização mais individualizada dos itinerários de aprendizagem, baseada em objetivos mais explícitos, coletas de informação mais qualitativas e regulares e intervenções mais diversificadas. Hoje, ainda, esse modelo cibernético mantém toda a sua validade, em um nível relativamente elevado de abstração, em qualquer ordem de ensino para qualquer disciplina escolar e qualquer aprendizagem.

Em resumo, a avaliação formativa não se faz sozinha, por isso é necessário que se mude a cultura da organização escolar, não só em escala de sala de aula, mas também de estabelecimento. Combater o individualismo dos professores e consequentemente de querer fazer como se quer, uma vez fechada a porta de sua sala de aula, pois a proposta se funda numa divisão do trabalho diferente entre os professores, porque a explicação dos objetivos, a elaboração dos testes com critérios ou a construção de seqüências didáticas ou de estratégias de adaptação ultrapassam as forças de cada um considerado isoladamente.

Dessa forma, a base é a divisão das tarefas, um desencerramento dos graus, uma colaboração entre professores que ensinam em classes paralelas ou na mesma disciplina. Da mesma forma, uma avaliação formativa poderia dar à administração escolar mais controle sobre a qualidade e a conformidade do ensino de uns e de outro, limitando a parcela das informações cifradas,e conduzindo a representações mais precisas daquilo que os alunos sabem fazer realmente.

Em vez de comparar taxas de fracassos ou médias de turmas, poder-se-iam comparar as aquisições reais e, portanto, distinguir mais claramente os professores mais e menos eficientes.

\section{Referências}

ALMEIDA, L. S. Aprendizagem escolar: dificuldades e prevenção. 1998. Em L. S. ALMEIDA e J. TAVARES (Orgs.), Conhecer, aprender, avaliar (pp.51-74). Porto: Porto Editora.

DARSIE, Maria Marta P. Avaliação da Aprendizagem. In: GT Formação de Professores. ANPED, 1995 (mimeo).

GATTI, Bernadete. Formação continuada de professores: a questão psicossocial. Cadernos de Pesquisa, São Paulo, n. 119, p. 191-204, julho 2003.

HOFFMANN, Jussara. Avaliação Mito \& Desafio: uma perspectiva construtivista. 18. ed. Porto Alegre: Mediação, 1995. 128 p.

LUCKESI, Cipriano. O educador: quem é ele. ABC Educatio .Outubro,2005. 
Avaliação da aprendizagem escolar: estudos e proposições. São Paulo: Cortez, 1995.

PERRENOUD, Philippe. Avaliação - da excelência à regulação das aprendizagens: entre duas lógicas. Trad. Patrícia Chittoni Ramos. Porto Alegre: Artes Médicas, 1999.

PERRENOUD, Philippe. Avaliação: da excelência à regulação das aprendizagens. Tradução Patrícia C. Ramos. Porto Alegre: Artmed, 1999.

SAUL, Ana Maria. Avaliação Emancipatória: desafio à teoria e à prática de avaliação e reformulação de currículo. 2. ed. São Paulo: Cortez, 1994.

TARDIF, Maurice. Saberes docentes e formação profissional. Petrópolis, RJ: Vozes, 2001.

VASCONCELOS, C. Métodos de Estudo em Alunos do $3^{\circ}$ Ciclo do Ensino Básico: Um contributo à intervenção educativa dos professores. Tese de Doutoramento. Braga: Universidade do Minho. 2000.

VEIGA, Ilma Passos Alencastro (coord.). Repensando a Didática. 22ª ed. Campinas: Papirus, 2005.

Sobre os Autores:

1. Mário Jorge de Araújo Gonzaga é Bacharel em Direito pela FAFIC de Cajazeiras, Licenciado em Geografia pela UECE-FAFIDAM. Especialista em Gestão Ambiental pela UFCG, Mestre em Ciências da Educação pela Universidad SanCarlos-PY.

E-mail: mariojorgeadvsth@hotmail.com.

2. Mônica Maria Siqueira Damasceno é Pedagoga, Professora do Instituto Federal do Ceará - IFCE, Mestranda em saúde da Criança e do Adolescente pela Universidade Estadual do Ceará - UECE. Especialista em psicologia Aplicada à Educação pela Universidade Regional do Cariri - URCA.

E-mail: siqueiramonica@ hotmail.com

3. Ana Cristina de Oliveira e Silva é graduada em farmácia, Especialista em Hematologia e Hemoterapia. Mestranda em saúde da Criança e do Adolescente pela Universidade Estadual do Ceará UECE. E-mail: Cristina_falconi@yahoo.com.br

4. Rita Edevanira de Sá Carneiro é graduada em Ciências Biológicas pela Universidade Regional do Cariri - URCA. Especialista em Gestão Escolar e em Mídias na Educação pela Universidade Federal do Ceará - UFC. E-mail: edevanira@ yahoo.com.br.

Como citar este artigo (Formato ISO):

GONZAGA, M.J.A.; DAMASCENO, M.M.S.; SILVA, A.C.O.S.; CARNEIRO, R.E.S. Avaliação versus práticas educativas. Id on Line Revista de Psicologia, Fevereiro de 2013, vol.1, n.19, p. 31-43. ISSN 19811189. 